\title{
Article
}

\section{Shifting Practice in the Diagnosis of Paediatric Coeliac Disease in English District General Hospitals}

Lee, Chai and Gordon, Morris

Available at http://clok.uclan.ac.uk/20598/

Lee, Chai and Gordon, Morris ORCID: 0000-0002-1216-5158 (2017) Shifting Practice in the Diagnosis of Paediatric Coeliac Disease in English District General Hospitals. Joural of Pediatric Gastroenterology and Nutrition . ISSN $0277-2116$

It is advisable to refer to the publisher's version if you intend to cite from the work. http://dx.doi.org/10.1097/MPG.0000000000001842

For more information about UCLan's research in this area go to http://www.uclan.ac.uk/researchgroups/ and search for <name of research Group>.

For information about Research generally at UCLan please go to http://www.uclan.ac.uk/research/

All outputs in CLoK are protected by Intellectual Property Rights law, including Copyright law. Copyright, IPR and Moral Rights for the works on this site are retained by the individual authors and/or other copyright owners. Terms and conditions for use of this material are defined in the policies page.

\section{CLoK}

Central Lancashire online Knowledge www.clok.uclan.ac.uk

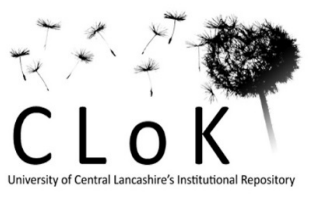




\section{Journal of Pediatric Gastroenterology \& Nutrition Shifting Practice in the Diagnosis of Paediatric Coeliac Disease in English District General Hospitals --Manuscript Draft--}

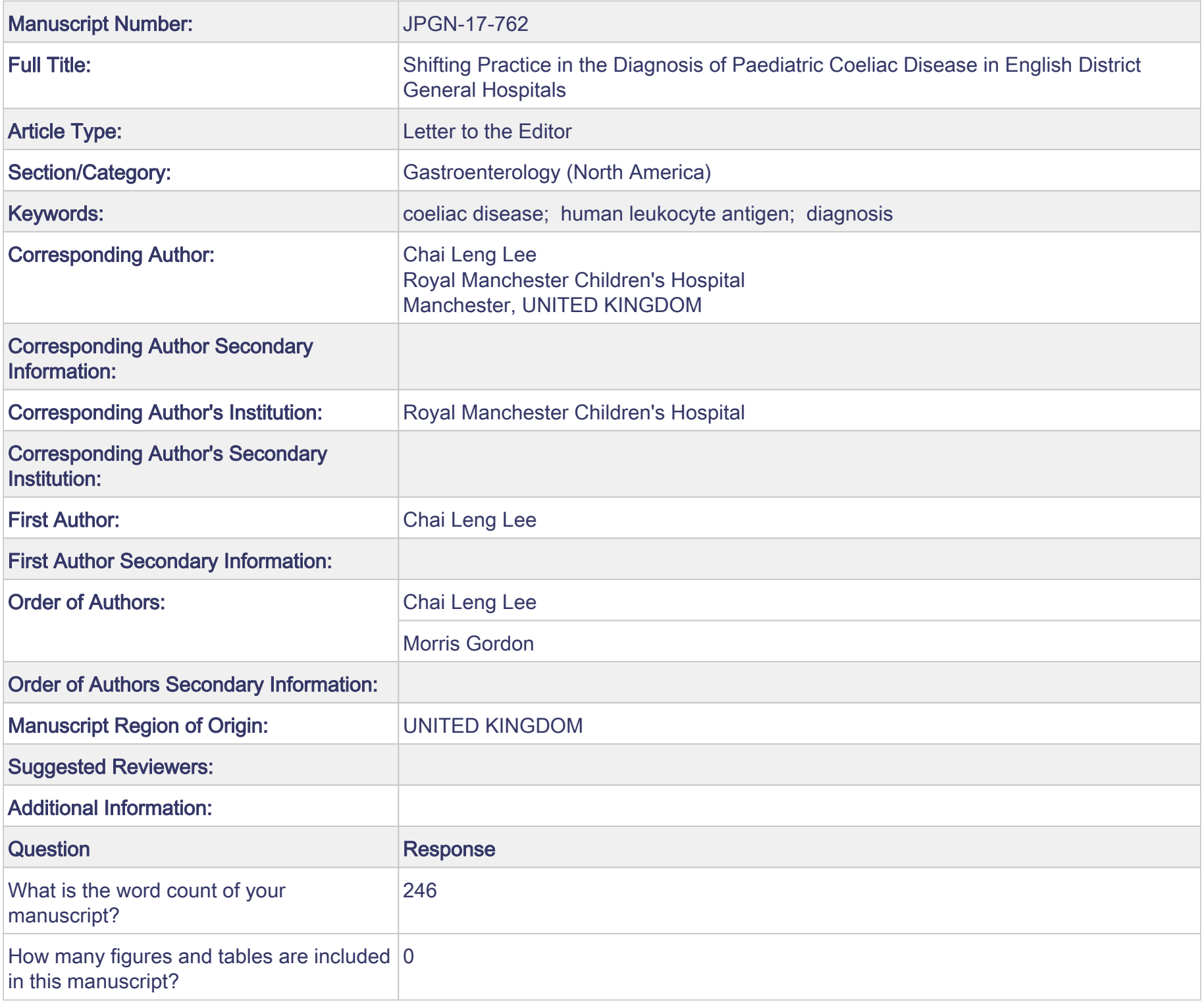


Dear Editor,

Thank you for considering this letter for publication in Journal of Pediatric Gastroenterology and Nutrition. While brief and concise, this study has gathered data in half of English hospitals on the changing practice of diagnosis of paediatric coeliac disease. It also raises a key issue of diverging practice between Europe and USA.

We hope you find it worthy of publication.

Kind regards,

Dr. Chai Leng Lee

\section{Statement of authorship}

M Gordon conceived the project, supported protocol design, analysis and contributed to final piece and approved. C.L.Lee led the protocol design, study, analysis, write up and approved final piece. 
Shifting Practice in the Diagnosis of Paediatric Coeliac Disease in English District General Hospitals.

Chai Leng Lee ${ }^{1} \mathrm{Mb}$ BCh, MRCPCH, Morris Gordon ${ }^{1,2}$ PHD

1.Department of Paediatrics,

Blackpool Victoria Hospital,

Whinney Heys Road,

Blackpool FY3 8NR

England, United Kingdom.

2. University of Central Lancashire

HA118 Harrington Building,

Preston, United Kingdom

Email: MGordon@uclan.ac.uk

Phone: 441253953443

Word count: 246 
Sir,

There are two major guidelines for CD within the UK; National Institute for Health and Care Excellence(NICE) ${ }^{1}$ and British Society of Paediatric Gastroenterology, Hepatology and Nutrition (BSPGHAN) ${ }^{2}$. The former advocates endoscopic biopsy with HLA testing reserved only in special circumstances for diagnosis, but the more contemporaneous latter advocates HLA detection combined with serology in symptomatic patients to diagnose CD.

To investigate actual practice, we performed a cross-sectional study of a whole sample of English district general hospitals from March-May 2017 with a response rate of $60 \%(n=70)$. Of these, $96 \%(n=67)$ reported to having some form of guidance. 59 units have recently shifted to using the BSPGHAN guidelines either as the primary source or in combination with other guidelines and only 5 units reported to the sole use of NICE guidelines. For those using BSPGHAN guidelines, $96 \%(n=56)$ would now make a diagnosis without endoscopic biopsy.

This almost universal uptake of BSPGHAN guidelines across England is clearly out of step with UK NICE guidance. More noteworthy is that the North American Society of Paediatric Gastroenterology, Hepatology and Nutrition (NASPGHAN) guidelines ${ }^{3}$ still recommends endoscopic biopsies as there are no standardisation of serological tests for CD within United States. ${ }^{4}$

The shifts in practice in England identified in this study demonstrates that global practice for diagnosis of paediatric CD is diverging between Europe and North America. Future work is needed to ascertain the sensitivity and specificity of diagnostic pathways employing HLA testing and to rationalise best practice globally.

\section{Reference}

1) National Institute for Health and Care Excellence (2015) Coeliac disease: recognition, assessment and management: NICE Guideline (NG20)

2) Murch S, Jenkins $H$, Auth $M$, et al. Joint BSPGHAN and Coeliac UK guidelines for the diagnosis and management of coeliac disease in children. Arch Dis Child 2013; 98:806-811.

3) Hill ID, Dirks MH, Liptak GS, et al. Guidelines for the Diagnosis and Treatment of Coeliac Disease in Children: Recommendations of the North American Society for Paediatric Gastroenterology, Hepatology and Nutrition. J Pediatr Gastroenterol Nutr 2005; 40:1-19.

4) Hill ID, Fasano A, Guandalini S, et al. NASPGHAN Clinical Report on the Diagnosis and Treatment of Gluten-related Disorders. J Pediatr Gastroenterol Nutr 2016;63: 156165 